\title{
CONSTITUCIONALISMO DIRIGENTE E ESTRATÉGIAS DE RECONHECIMENTO: A JUDICIALIZAÇÃO DA POLÍTICA NA LUTA POR ESTIMA SOCIAL
}

Victor Fernando Alves Carvalho ${ }^{1}$

\section{Resumo:}

Este trabalho busca refletir sobre o constitucionalismo dirigente $\mathrm{e}$ as teorias do reconhecimento. Nelson Moreira defende que uma Teoria da Constituição adequada a países de modernidade tardia como o Brasil, além de enfatizar o papel da Jurisdição Constitucional, deve dar centralidade ao povo e aos movimentos sociais na construção do sentimento constitucional, por meio de uma cidadania ativista apta a promover reconhecimento para os grupos historicamente excluídos. Este artigo traz a reflexão de que a judicialização da política e a disputa pela interpretação constitucional se tornaram estratégias centrais de grupos minoritários na luta por reconhecimento e estima social.

Palavras-chave: Dirigismo constitucional; reconhecimento; judicialização; sentimento constitucional; cidadania ativista.

\section{DIRECTING CONSTITUTIONALISM AND RECOGNITION STRATEGIES: THE JUDICIALIZATION OF POLITICS IN THE STRUGGLE FOR SOCIAL ESTEEM}

\begin{abstract}
:
This paper seeks to reflect on the directing constitutionalism and the theories of recognition. Nelson Moreira argues that a Theory of the Constitution suitable for countries of late modernity such as Brazil, in addition to emphasizing the role of Constitutional Jurisdiction, should give centrality to the people and social movements in the construction of constitutional sentiment, through an activist citizenship able to promote recognition for historically excluded groups. This paper argues that the judicialization of politics and the dispute for constitutional interpretation have become central strategies of minority groups in the struggle for recognition and social esteem.
\end{abstract}

Keywords: Directing constitutionalism; recognition; judicialization; constitutional sentiment; activist citizenship.

\section{Considerações iniciais}

No presente trabalho, pretende-se fazer uma reflexão crítica sobre a ideia de Moreira (2008), formulada a partir do conceito de sentimento constitucional de Lucas Verdú (2004), de que a Constituição Brasileira de 1988 somente conseguirá exercer seu caráter dirigente se

\footnotetext{
${ }^{1}$ Bacharel em Direito pela Universidade Federal de Sergipe (2018) e mestrando pelo Programa de PósGraduação em Direito da mesma instituição (concentração: Constitucionalização dos Direitos). Advogado. Email: victorfernandocarvalho@gmail.com
} 
for fomentado um sentimento constitucional e se for promovida uma ética do reconhecimento. A reflexão gira em torno da judicialização da política impulsionada por movimentos sociais e grupos de interesse como uma luta por estima social, na terceira dimensão da tipologia de Axel Honneth sobre o reconhecimento. Para a compreensão da interface entre reconhecimento e constitucionalismo, o presente artigo fundamenta-se na tese de Moreira $(2008,2010)$ sobre dirigismo constitucional, ética do reconhecimento e sentimento constitucional.

A ideia de Moreira é que, por uma série de fatores históricos, foi criada uma classe gigantesca de subcidadãos no Brasil, com base na apropriação privada do espaço público por elites socioeconômicas, o que impediu a concretização do projeto da Modernidade fundamentado no princípio da igualdade. Nesse sentido, a massa subcidadã, por não se enxergar nas promessas da Constituição e por não se ver refletida nos compromissos reais do ordenamento jurídico, não desenvolve um sentimento constitucional. Mesmo que existam instituições públicas fortes que cumpram as promessas constitucionais, ainda assim a construção de um sentimento constitucional depende diretamente de uma cidadania ativista, em que os tidos subcidadãos se tornam protagonistas da luta por direitos, numa Teoria da Constituição que não reserva à Jurisdição Constitucional somente, mas sim ao povo, um lugar privilegiado. Dessa forma, sem uma cidadania ativista se faz inviável haver uma Constituição Dirigente num país de Modernidade tardia como o Brasil.

Nesses termos, o pensamento de Moreira (2008) articula o caráter dirigente da Constituição com uma política ou ética do reconhecimento, pois essa articulação, segundo o autor, é capaz de promover o sentimento constitucional. Dando ênfase ao sentimento constitucional, ao lado da Jurisdição Constitucional, tem-se uma Teoria da Constituição que confere tanto à Jurisdição quanto aos movimentos sociais e ao povo uma centralidade suficiente, diferentemente de Teorias da Constituição mais tradicionais, que conferem somente ao Poder Constituinte Originário e às instituições um protagonismo que, na verdade, não lhes pertence somente, mas que também diz respeito às lutas de grupos sociais. Afinal, o sentimento de estima das pessoas pode e é construído pelas próprias pessoas, de forma autônoma, nas lutas sociais por direitos.

Dessa forma, as instituições têm um papel relevante no cumprimento das normas constitucionais, porém a ética do reconhecimento não depende exclusivamente das instâncias oficiais de poder, sendo diretamente influenciada pelo desenrolar das lutas sociais. 
Assim, a consolidação de um sentimento constitucional no Brasil não depende apenas de quão comprometidas com uma política do reconhecimento estiverem as instituições públicas (MOREIRA, 2008). Depende também das lutas sociais, que são o elemento propulsor da ética do reconhecimento. O que acaba positivado nas legislações, bem como o que restou positivado na Constituição Federal, dependeu diretamente do nível de organização e mobilização de segmentos sociais e grupos minoritários na defesa de seus direitos. Desse modo, o quanto uma pessoa se sente reconhecida diz respeito ao quanto suas lutas sociais conseguem repercutir junto às instâncias de poder. Por essa razão, uma política do reconhecimento não é algo que está nas mãos da Jurisdição Constitucional simplesmente fazer ou deixar de fazer, sendo, na verdade, algo que está nas mãos das lutas sociais buscar ou não buscar, numa cidadania efetivamente ativista, apta a conferir ao projeto constitucional de 1988 um caráter dirigente. O que acontece na instância oficial é consequência de mobilizações de segmentos da sociedade interessados em fortalecer o princípio da igualdade, estando nesses segmentos, portanto, a centralidade da discussão, e não na Jurisdição Constitucional tão somente.

Feitas essas considerações iniciais, pretende-se, em primeiro lugar, apresentar a ideia de Moreira que articula o dirigismo constitucional e a ética do reconhecimento. Esse é o capítulo I. No capítulo II, busca-se apresentar a ética do reconhecimento de Axel Honneth, bem como a de Charles Taylor. No capítulo III, objetiva-se destacar que, seja a ética de Charles Taylor (referenciada por Moreira), seja a de Axel Honneth, ambas se referem ao reconhecimento intersubjetivo como fruto de conflitos sociais, e não como benesses de instâncias de poder. Nessa linha de raciocínio, busca-se discutir que a mobilização de movimentos sociais e grupos de interesse, enquanto uma das causas da judicialização da política, enquadra-se na luta por estima social, classificada por Honneth na terceira dimensão do reconhecimento intersubjetivo - a solidariedade. Conclui-se discutindo que apenas a centralidade das lutas sociais é capaz de construir uma ética do reconhecimento e, assim, promover um sentimento cidadão, para além de um sentimento constitucional. Como técnica de pesquisa, utilizou-se a revisão bibliográfica, por meio da leitura crítica dos autores de referência na área pesquisada.

\section{Capítulo I: dirigismo constitucional e a ética do reconhecimento}


Conforme Moreira (2008, p. 88), a ideia de constitucionalismo dirigente é basicamente portuguesa, advinda da Constituição de Portugal de 1976, elaborada por Gomes Canotilho, que apontava como superada a existência de normas constitucionais meramente programáticas. Aplicando-se a ideia ao Brasil, se faz necessário pensar num constitucionalismo dirigente que seja adequado a países da chamada modernidade tardia, “como tentativa de defesa diante dos devastadores 'ataques neoliberais' ao Estado brasileiro e de luta pela proteção dos direitos fundamentais [...] e pela contínua construção da democracia” (MOREIRA, 2008, p. 88). O autor pretende, portanto, construir uma teoria constitucional adequada ao Brasil enquanto país periférico, "no qual o Estado social foi um simulacro, e que sofre com o impacto da globalização neoliberal” (MOREIRA, 2008, p. 89).

Os impactos da globalização nos países periféricos apontam para a necessidade da reinserção, no Direito, de um pano de fundo ético, fundamentado nos valores universais da pessoa humana, como liberdade, igualdade e fraternidade, lidos não como meras noções abstratas, mas sim como constructos concretizáveis. Autores como Ricardo Sayeg e Wagner Balera chegam a formular uma tese de defesa de um capitalismo humanista (2011), ante a necessidade urgente de impor ao capitalismo os contornos limitativos dos direitos humanos. “O liberalismo e sua transposição para o direito são convenientes naquelas ordens soberanas em que não há graves déficits de concretização desses direitos [humanos de segunda e terceira dimensões]" (SAYEG, BALERA, 2011, p. 164), afinal na ordem neoliberal a tendência é sempre que os ricos fiquem mais ricos e os pobres fiquem mais pobres. Um humanismo antropofilíaco não admite indiferença à pobreza e aos destinos do planeta; pelo contrário, exige que a devida atenção aos direitos humanos de segunda e terceira dimensões supere preocupações de ordem exclusivamente financeira.

Nesse contexto de denúncia quanto aos impactos da globalização neoliberal, Moreira aponta para a relação existente entre o sistema democrático e os direitos fundamentais (2008, p. 97), na medida em que tanto o primeiro quanto o segundo são pressupostos para a concretização do projeto constitucional promulgado em 1988. O intuito das personagens constituintes de 1988 não foi simplesmente fundar um Estado liberal, que garanta uma esfera inviolável de liberdade da pessoa humana frente ao poder do Estado, mas sim "dar um fundamento ético à nova ordem constitucional brasileira, tomando-a como estrutura normativa que incorpora os valores de uma comunidade histórica concreta" (MOREIRA, 2008, p. 97), isso por meio da referência positivada a valores fundamentais da ordem constitucional, 
sobretudo a primazia da dignidade da pessoa humana. Mesmo que esses valores estejam democraticamente definidos e positivados, suas possibilidades e prioridades de aplicação estão em aberto, demandando, portanto, do jurista uma hermenêutica apropriada a cada caso.

Conclui Moreira que os dois pilares fundamentais do projeto constitucional de 1988 são "a proteção e efetivação dos direitos humanos e a sedimentação da democracia" (2008, p. 99). Nessa linha de raciocínio, os compromissos assumidos pela Constituição, em especial em seus três primeiros artigos, levam-na a ser classificada como uma Constituição Dirigente, ideia divulgada inicialmente por Gomes Canotilho tendo como enfoque a Constituição de Portugal de 1976, que buscava superar a noção de normas meramente programáticas, como já dito, visando, no caso português, a uma transição gradual para o regime socialista, conforme seu primeiro artigo - atualmente já revogado. De acordo com Moreira, o modelo português de Constituição Dirigente inspirou os membros da Constituinte brasileira de 1988, na medida em que "os agentes do Poder Constituinte originário submetem os futuros governos e a sociedade à realização de princípios constitucionalmente aventados para a transformação da realidade social” (MOREIRA, 2008, p. 100). Contudo, o próprio Canotilho faz a ressalva de que “[...] a Constituição dirigente está morta se o dirigismo constitucional for entendido como normativismo constitucional revolucionário capaz de, por si só, operar transformações emancipatórias" (CANOTILHO, 2001, p. XXIX).

$\mathrm{Na}$ realidade brasileira, há uma parcela gigantesca da população vitimada pela ausência histórica de políticas públicas de inclusão social, vivendo, assim, numa condição de subcidadania. Segundo Moreira, "a construção hermenêutica de um sentimento constitucional pode ser o elo entre a situação de indignidade humana e o estágio social mais justo conforme prometido pelo art. $3^{\circ}$ da Constituição brasileira" (2008, p. 105). Nesse caso, é fundamental a atuação do Estado, diferentemente do que prega a filosofia neoliberal. O processo de globalização assumiu nos países periféricos uma ferocidade destrutiva para a concretização dos direitos fundamentais, razão pela qual os intérpretes da Constituição podem e devem se valer do arcabouço do dirigismo constitucional para proteger os direitos humanos em face das mazelas do neoliberalismo, que é indiferente à pobreza e à miséria, por isso mostrando-se logicamente incompatível com um projeto constitucional assentado nos direitos humanos e na democracia. Essa mudança de enfoque, que passa a privilegiar a Jurisdição Constitucional, redimensiona os conceitos do Estado de Direito, na medida em que exige dos intérpretes uma postura ativa na construção do sentimento constitucional, a partir de uma hermenêutica que 
considere a amplitude da dignidade humana na Constituição de 1988, até mesmo por razões topográficas (MOREIRA, 1988, p. 114).

A precariedade da cidadania no Brasil aponta, conforme Moreira (2008, p. 116), para a necessidade de intervenções estatais básicas, que efetivem os direitos sociais. Tão relevante quanto uma postura ativa da Jurisdição Constitucional, no entanto, é a construção de uma tradição hermenêutica de um sentimento constitucional, para a concretização dos compromissos da Modernidade, dos direitos sociais e dos objetivos demarcados pelo texto constitucional. Segundo Lucas Verdú (2004), o sentimento constitucional é o liame moral entre os indivíduos e as instituições, na medida em que aqueles, movidos por uma cidadania ativista, buscam exigir o cumprimento das promessas constitucionais por estas.

Portanto, pode-se resumir a ideia de Moreira em alguns pontos (2008, p. 117-118): a) a Constituição de 1988 foi revolucionária no sentido de promover um resgate ético do Direito, ao fundamentar a ordem jurídica a partir de valores morais da pessoa humana, em especial a dignidade da pessoa humana; b) a Constituição assume um caráter dirigente na medida em que estabelece metas bem definidas para a concretização dos direitos sociais, superando a noção de normas meramente programáticas, em benefício sobretudo das parcelas da população historicamente marginalizadas, excluídas e enquadradas numa condição de subcidadania; c) além da atuação da Jurisdição Constitucional, se faz necessário o fomento do sentimento constitucional, o que demanda a construção de uma cidadania ativista no Brasil, “capaz de, ao lado da própria Jurisdição constitucional, implementar as promessas descumpridas da modernidade" (MOREIRA, 2008, p. 118).

Nesses termos, apesar de caber à Jurisdição Constitucional a guarda das promessas constitucionais, é necessário ter uma visão realista e reconhecer que "boa parte daqueles que detêm o poder de atuar judicialmente em prol da efetivação do texto dirigente não o fazem" (MOREIRA, 2010, p. 32). Afirma Moreira:

\footnotetext{
A partir do momento em que não há um comprometimento com o sentimento constitucional, fragiliza-se a concretização do discurso efetivador de políticas sociais. E, além disso, também se corre o risco, quando se depositam todas as fichas do Estado Democrático de Direito no Judiciário, de se ver os excessos praticados por este que, extasiado de poder, pode se arvorar na condição de superego da sociedade. $\mathrm{Na}$ verdade, quando se fala em sentimento constitucional, fala-se diretamente do sentimento de pertencimento do povo, não de uma minoria (privilegiada) do povo, mas de todo o povo à Constituição, entendida não como uma carta utópica, mas como um plano de atuação capaz de conduzir permanentemente os rumos de um Estado brasileiro, que ainda precisa (e muito!) assumir-se como social (MOREIRA, 2010, p. 32, grifo ausente no original).
} 
Portanto, dar ênfase à Jurisdição Constitucional por si só é insuficiente, pois a construção de um sentimento constitucional também depende diretamente da articulação dos movimentos sociais e grupos de interesse da sociedade civil em lutarem coletivamente pela concretização das metas constitucionais. Nesses termos, os grupos sociais, em sua luta por reconhecimento, passam a utilizar a Constituição como peça central de sua cidadania ativista. Assim, por razões metodológicas, propõe-se, no próximo capítulo, compreender as filosofias políticas de Charles Taylor e Axel Honneth, ambos teóricos do reconhecimento, antes de investigar de que forma a Constituição aparece nas lutas sociais de uma cidadania ativista.

\section{Capítulo II: teorias do reconhecimento de Taylor e Honneth}

A tese de Charles Taylor é de que:

[...] nossa identidade é moldada em parte pelo reconhecimento ou por sua ausência, frequentemente pelo reconhecimento errôneo por parte dos outros, de modo que uma pessoa ou grupo de pessoas pode sofrer reais danos, uma real distorção, se as pessoas ou sociedades ao redor deles lhes devolverem um quadro de si mesmas redutor, desmerecedor ou desprezível. $O$ não-reconhecimento ou o reconhecimento errôneo podem causar danos, podem ser uma forma de opressão, aprisionando alguém numa modalidade de ser falsa, distorcida e redutora (TAYLOR, 2000, p. 241, grifos ausentes no original).

Segundo o filósofo, o reconhecimento errôneo não significa simplesmente faltar ao respeito com alguém ou todo um grupo; chega ao ponto de poder aprisionar suas vítimas "num paralisador ódio por si mesmas" (TAYLOR, 2000, p. 242). O reconhecimento tampouco simboliza uma mera cortesia que se deve conceder às pessoas, pois se trata, na verdade, de uma necessidade humana fundamental, a que se tem dado a atenção necessária somente na Modernidade, em virtude de duas transformações vitais: o colapso das hierarquias sociais, base da honra, modernamente substituída pela noção de dignidade, num sentido universalista e igualitário; bem como a nova compreensão de identidade individual, a partir do fim do século XVIII, como um ideal de autenticidade (ser fiel a si, à sua maneira particular de ser no mundo).

Esta última virada paradigmática, segundo Taylor, deve-se sobretudo à filosofia de J. G. Herder, para quem existe um certo modo de ser humano que é o modo exclusivo da pessoa. "Sou chamado a levar minha vida assim, e não imitando a vida de outrem. Mas essa noção dá uma nova relevância ao ser fiel a mim mesmo. Se não o for, perderei o sentido de minha vida, ficarei privado do que é ser humano para mim" (TAYLOR, 2000, p. 245). Esse ideal de autenticidade amplia a relevância do autoconhecimento porque introduz o princípio da 
originalidade - toda voz tem algo a dizer porque cada voz é única. "Não só não devo moldar minha vida de acordo com as exigências da conformidade externa como sequer posso encontrar fora de mim o modelo pelo qual viver. Só o posso encontrar dentro de mim" (TAYLOR, 2000, p. 245). O ideal de autenticidade, ao emergir na Modernidade a partir de Herder, conclama as pessoas a descobrirem sua maneira única e singular de ser, uma maneira original de ser que se gera do interior da pessoa, e não do exterior (padrões sociais).

Para compreender esse novo ideal da Modernidade, é necessário reconhecer, segundo Taylor, um característica crucial da vida humana - sua dialogicidade. "Tornamo-nos agentes humanos plenos, capazes de nos compreender a nós mesmos e, por conseguinte, de definir nossa identidade, mediante a aquisição de ricas linguagens humanas de expressão" (TAYLOR, 2000, p. 246), linguagens a que as pessoas são apresentadas por meio da interação com outras pessoas valiosas em suas vidas, os "outros significativos" (termo que Taylor emprega a partir de G. H. Mead). "A gênese do espírito humano é, nesse sentido, não monológica, não algo que cada pessoa realiza por si mesma, mas dialógica" (TAYLOR, 2000, p. 246).

Dessa forma, as pessoas definem suas próprias identidades no diálogo permanente com as expectativas dos outros significativos, e com frequência em luta contra essas expectativas, conforme afirma Taylor (2000, p. 246). Por essa razão, “minha descoberta de minha identidade não implica uma produção minha de minha própria identidade no isolamento; significa que eu a negocio por meio do diálogo, parte aberto, parte interno, com o outro" (TAYLOR, 2000, p. 248, grifo ausente no original). O reconhecimento passa, então, a figurar como peça central tanto a nível íntimo, quanto a nível social, pois uma política contínua de igual reconhecimento passa a sustentar as democracias saudáveis, nas quais a noção de dignidade é universalizada como algo inerente a todos os seres humanos, algo de que todos partilham, diferentemente da honra que, para funcionar, precisa pertencer a algumas pessoas e a outras não (TAYLOR, 2000, p. 242).

Com a universalização da dignidade, passa-se a evitar a fragmentação da cidadania em classes (cidadãos de primeira e de segunda classe), e medidas reais e objetivas passaram a ser tomadas no plano político com base nesse princípio, como a ampliação dos direitos civis aos negros, nos Estados Unidos dos anos 60. "Pessoas sistematicamente impedidas pela pobreza de fruir o máximo de seus direitos de cidadania são consideradas, dessa perspectiva, relegadas a um status de segunda classe, o que requer uma ação corretiva pela via da 
equalização" (TAYLOR, 2000, p. 250). Nesse cenário, algo inédito acontece: o princípio de cidadania igual para todos obtém aceitação universal. Essa rejeição terminativa à divisão das pessoas em cidadãos de primeira e segunda classe é o combustível da cidadania ativista, eixo central do constitucionalismo dirigente, consoante Moreira $(2008,2010)$ e aqui discutido.

Quanto ao reconhecimento da universalização da dignidade na comunidade internacional, no século XX, Bobbio aponta para a relevância da Declaração Universal dos Direitos Humanos de 1948, na medida em que este documento estabeleceu, pela primeira vez na história, um consenso internacional em torno de um sistema de valores mínimos para o comportamento humano:

Não sei se se tem consciência de até que ponto a Declaração Universal representa
um fato novo na história, na medida em que, pela primeira vez, um sistema de
princípios fundamentais da conduta humana foi livre e expressamente aceito, através
de seus respectivos governos, pela maioria dos homens que vive na Terra. Com essa
declaração, um sistema de valores é - pela primeira vez na história - universal,
não em princípio, mas de fato, na medida em que o consenso sobre sua validade
e sua capacidade para reger os destinos da comunidade futura de todos os
homens foi explicitamente declarado (BOBBIO, 2004, p. $27-28$, grifo ausente no
original).

No entanto, segundo Taylor, a política de reconhecimento na esfera pública não se esgotou numa política de igual dignidade para todos os cidadãos, com base na universalização dos direitos. Ocorreu uma segunda mudança: a construção de uma política da diferença, também de base universalista, a significar que todas as pessoas devem ter reconhecida sua identidade peculiar. De acordo com Taylor, a política da diferença fundamentou-se em denúncias consistentes de grupos minoritários de que padrões culturais hegemônicos produziram e produzem cidadanias de segunda classe. Daí a importância de existir uma política da diferença paralelamente à universalização da dignidade:

[...] com a política da dignidade igual, aquilo que é estabelecido pretende ser universalmente o mesmo, uma cesta idêntica de direitos e imunidades; com a política da diferença, pedem-nos para reconhecer a identidade peculiar desse indivíduo ou grupo, aquilo que o distingue de todas as outras pessoas. A ideia é de que é precisamente esse elemento distintivo que foi ignorado, assimilado a uma identidade dominante ou majoritária. $\mathbf{E}$ essa assimilação é o pecado capital contra o ideal da autenticidade (TAYLOR, 2000, p. 250-251, grifos ausentes no original).

Dessa forma, a política da igual dignidade fundamenta-se na ideia de que todas as pessoas são dignas de respeito. Uma das formulações mais influentes para essa política foi a kantiana: por sermos todos agentes racionais, todos merecemos igual respeito. Ao mesmo tempo, a política da diferença exige que se respeite o potencial humano universal de definir a 
própria identidade e, portanto, se atribua igual valor ao que as pessoas concretamente fazem desse potencial (TAYLOR, 1999, p. 253).

Embora pareça existir certa contradição entre as duas, o contraponto da segunda política em relação à primeira é relevante na medida em que denuncia o caráter inconscientemente discriminatório da ideia de uma sociedade cega às diferenças, pois o vácuo deixado pela neutralidade é sempre ocupado pelos padrões culturais hegemônicos:

[...] a acusação lançada pelas modalidades mais radicais da política da diferença é a de que os liberalismos cegos são eles mesmos reflexo de culturas particulares. E o pensamento preocupante é de que essa tendenciosidade possa não ser apenas uma fraqueza das teorias até agora propostas, de que a própria ideia de tal liberalismo possa ser uma espécie de contradição pragmática, um particularismo mascarado de universal (TAYLOR, 2000, p. 254, grifos ausentes no original).

A filosofia do reconhecimento de Charles Taylor exerce uma papel fundamental na Modernidade. Contudo, além dele, também é necessário destacar a contribuição de Axel Honneth. "Nenhum outro pensador moderno, além de Charles Taylor, contribuiu tão decisivamente para a renovação do paradigma da teoria crítica do reconhecimento quanto o filósofo e sociólogo alemão Axel Honneth” (MATTOS, 2006, p. 87).

Partindo dos escritos do jovem Hegel, Honneth afirma que o reconhecimento de si é necessariamente intersubjetivo: "só quando dois indivíduos se veem confirmados em sua autonomia por seu respectivo defrontante, eles podem chegar de maneira complementária a uma compreensão de si mesmos como um $\mathrm{Eu}$ autonomamente agente e individuado" (HONNETH, 2003, p. 119-120). No entanto, mesmos nos escritos hegelianos já há a intuição de que existem diversas maneiras de reconhecimento recíproco, que se distinguem de acordo com o grau de autonomia conquistado pelo sujeito. Esses modos diferentes de reconhecimento corresponderiam ao amor, ao direito e à eticidade, "em cujo quadro os indivíduos se confirmam reciprocamente como pessoas autônomas e individuadas, em uma medida cada vez maior" (HONNETH, 2003, p. 121, grifo ausente no original).

Honneth afirma que a psicologia social de George Herbert Mead, ao fundamentar sob pressupostos naturalistas a teoria hegeliana do reconhecimento, conseguiu desenvolver da maneira mais consequente possível a ideia de que as pessoas devem suas identidades à experiência do reconhecimento recíproco (HONNETH, 2003, p. 125). A partir do momento em que o indivíduo desencadeia em si próprio a mesma reação que seu comportamento estimulou no seu defrontante, ele consegue se conscientizar sobre si mesmo. Em outras palavras, essa autorrelação originária, em que o indivíduo se percebe pela primeira vez na 
condição de objeto, resulta em seu primeiro quadro de si, o que Mead chamou de "Me". Dessa forma, "um sujeito só pode adquirir uma consciência de si mesmo na medida em que ele aprende a perceber sua própria ação da perspectiva, simbolicamente representada, de uma segunda pessoa" (HONNETH, 2003, p. 131).

$\mathrm{O}$ "Me", portanto, na categorização de Mead, é a imagem cognitiva que o sujeito forma de si mesmo quando passa a se perceber da perspectiva de outra pessoa. Essa autoimagem cognitiva se transforma numa autoimagem prática quando o indivíduo, "ao se colocar na perspectiva normativa de seu parceiro de interação, assume suas referências axiológicas morais, aplicando-as na relação prática consigo mesmo" (HONNETH, 2003, p. 133). À medida que ocorre o processo de socialização da criança, ela interioriza as normas de ação que advém da generalização das expectativas comportamentais de todos os membros da sociedade (o "outro generalizado", na categorização de Mead). É dessa forma que a psicologia social de Mead emprega o conceito de reconhecimento para as relações intersubjetivas: "na medida em que a criança em desenvolvimento reconhece seus parceiros de interação pela via da interiorização de suas atitudes normativas, ela própria pode saber-se reconhecida como um membro de seu contexto social de cooperação" (HONNETH, 2003, p. 136-137).

$\mathrm{O}$ "Me", contudo, não define sozinho a psique, pois tem uma contraparte inconsciente, o "Eu". Enquanto o primeiro recebe as normas sociais e as interioriza para o sujeito se comportar conforme as expectativas sociais, o segundo recebe os impulsos internos que reagem involuntária e criativamente contra as normas sociais. $\mathrm{O}$ atrito interno entre o "Me" e sua contraparte psíquica, o "Eu", define, nessa linha de raciocínio, o desenvolvimento moral tanto a nível individual quanto social:

[...] o "Me" incorpora, em defesa da respectiva coletividade, as normas convencionais que o sujeito procura constantemente ampliar por si mesmo, a fim de poder conferir expressão social à impulsividade e criatividade do seu "Eu". [...] É a existência do "Me" que força o sujeito a engajar-se, no interesse de seu "Eu", por novas formas de reconhecimento social. [...] ele precisa, se quiser realizar as exigências de seu "Eu", antecipar uma coletividade na qual lhe cabe uma pretensão à realização do desejo correspondente. [...] no lugar do "outro generalizado" da coletividade existente entra, portanto, aquele de uma sociedade futura, na qual as pretensões individuais encontrarão presumivelmente assentimento (HONNETH, 2003, p. 141-142).

Dessa forma, a evolução social é forçada pela necessidade permanente de adaptação aos processos de liberação da individualidade, que se materializaram na ampliação jurídica dos direitos de liberdade. Tanto Hegel quanto Mead concordam, segundo Honneth, que a liberação da individualidade funciona como o motor de uma permanente luta por 
reconhecimento, na medida em que "os sujeitos procuram ininterruptamente ampliar a extensão dos direitos que lhes são intersubjetivamente garantidos e, nesse sentido, elevar o grau de autonomia pessoal" (HONNETH, 2003, p. 145). Ademais, tanto a teoria de Mead quanto a hegeliana estabelecem uma distinção entre três formas de reconhecimento recíproco: a dedicação emotiva (relações amorosas), o reconhecimento jurídico e o assentimento solidário. Conforme Honneth (2003, p. 157-158), já aparecia em Hegel a ideia de que a autonomia do indivíduo se amplia com cada etapa de reconhecimento, mas somente em Mead aparece a "hipótese empírica, segundo a qual o grau de relação positiva da pessoa consigo mesma se intensifica passo a passo na sequência das três formas de reconhecimento" (HONNETH, 2003, p. 158). Passa-se, a seguir, ao exame de cada uma dessas três maneiras de reconhecimento recíproco.

Em primeiro lugar, as relações amorosas não consistem na intimidade do sexo, mas sim nas relações primárias do indivíduo. Segundo Honneth, Hegel já intuía que "na experiência recíproca da dedicação amorosa, dois sujeitos se sabem unidos no fato de serem dependentes, em seu estado carencial, do respectivo outro" (2003, p. 160). Neste ponto, Honneth recorre aos escritos do psicanalista Winnicott, cuja abordagem diferenciada, de acordo com o filósofo, permite que sua percepção seja compatibilizada com o referencial teórico de Hegel e Mead.

Para Winnicott, os primeiros meses de vida da criança representam uma simbiose da criança com a mãe, uma fase de intersubjetividade indiferenciada, em que o bebê depende de tal modo dos cuidados maternos que não pode ser estudado sem a pessoa referencial, a mãe. Trata-se de um estado do indiferenciado ser-um, em que o bebê percebe os cuidados da mãe como uma manifestação da própria onipotência, ao mesmo tempo em que a mãe percebe as reações do bebê como componentes do mesmo ciclo de ação.

Nesse sentido, a preocupação de Winnicott era entender como mãe e filho superam o estado de simbiose para se aceitar e se amar como pessoas independentes. Para tanto, primeiro descreve o que chamou de fase de dependência absoluta, em que os dois parceiros de interação dependem completamente um do outro para a satisfação de suas necessidades, de tal modo que há uma indistinção emotiva e física entre a mãe e o bebê (HONNETH, 2003, p. 166). A partir do momento em que a mãe retorna para as atividades do cotidiano, e o tempo que passa com o bebê diminui, começa a fase da dependência relativa, pois a própria dependência do bebê em relação à mãe entra no campo de visão daquele. 
A criança, nessa fase, vive um processo de desilusão, pois se dá conta de que a mãe, aquele ser que estava à sua inteira disposição, escapa agora de seu controle onipotente. Passa a adotar, então, comportamentos agressivos e de destruição, como forma de vivenciar a nova percepção de que ela depende da atenção de um ser que existe independentemente dela, um ser autônomo com pretensões próprias (HONNETH, 2003, p. 170). "Se a mãe soube passar pelo teste de seu filho, tolerando os ataques agressivos sem a vingança de privá-lo do amor, então, da perspectiva dele, ela pertence de agora em diante a um mundo exterior aceito com dor" (HONNETH, 2003, p. 173). A criança, sentindo-se segura pela durabilidade e confiabilidade do amor da mãe, desenvolve a capacidade de estar só. Dessa forma, o autorrespeito, a confiança elementar em si mesmo, precede as outras formas de reconhecimento recíproco e advém da "segurança emotiva de que a pessoa amada preserva sua afeição mesmo depois da autonomização renovada" (HONNETH, 2003, p. 178).

Do reconhecimento amoroso se distingue o reconhecimento jurídico. No caso do direito, “apenas da perspectiva normativa de um 'outro generalizado', que já nos ensina a reconhecer os outros membros da coletividade como portadores de direitos, nós podemos nos entender também como pessoa de direito" (HONNETH, 2003, p. 179). No pensamento hegeliano, o reconhecimento jurídico é dependente da Modernidade e de suas premissas de princípios morais universalistas. Na medida em que somente se pode esperar dos parceiros de interação que obedeçam às normas jurídicas se puderem assentir a elas na qualidade de seres livres e iguais, "migra para a relação de reconhecimento do direito uma nova forma de reciprocidade, altamente exigente: obedecendo à mesma lei, os sujeitos de direito se reconhecem reciprocamente como pessoas capazes de decidir com autonomia individual sobre normas morais" (HONNETH, 2003, p. 182).

Dessa forma, com a transição para a Modernidade, os direitos individuais não dependem mais das expectativas provenientes de papeis sociais ou de status, mas passam a pertencer a todo indivíduo, na qualidade de ser livre. Quando as relações jurídicas eram baseadas na tradição, o reconhecimento como pessoa de direito dependia da estima social que o indivíduo recebia em seu status. O reconhecimento jurídico podia, então, ser dividido em graus, de acordo com a estima social que o indivíduo possuía enquanto portador de um papel social; contudo, na passagem para a Modernidade, o reconhecimento como pessoa de direito passa a ser aplicado a todo sujeito em igual medida, apartando-se do grau de estima social. Do desacoplamento entre o reconhecimento jurídico e a estima social decorre que aquele não 
tolera mais qualquer graduação, enquanto a estima necessariamente remete a critérios de graduação (quem tem mais estima e quem tem menos):

[...] em ambos os casos, como já sabemos, um homem é respeitado em virtude de determinadas propriedades, mas no primeiro caso se trata daquela propriedade universal que faz dele uma pessoa; no segundo caso, pelo contrário, trata-se das propriedades particulares que o caracterizam, diferentemente de outras pessoas (HONNETH, 2003, p. 187).

Nas primeiras décadas do século XX, segundo Honneth (2003, p. 191), as exigências de igualdade de grupos minoritários movimentaram a luta por reconhecimento jurídico de tal modo que se impôs em definitivo a convicção de que se aplica a todo membro da coletividade o igual direito à participação política. Isso só foi possível tendo em vista que todas as comunidades jurídicas modernas, "unicamente porque sua legitimidade se torna dependente da ideia de um acordo racional entre indivíduos em pé de igualdade, [estão fundadas] na assunção da imputabilidade moral de todos os seus membros" (HONNETH, 2003, p. 188). De todo modo, o enriquecimento das pretensões jurídicas individuais pode ser lido como um processo permanente, pois grupos desfavorecidos se dão conta de que não lhes foi dada a condição necessária para a igual participação no acordo racional que justifica a ordem jurídica e, assim, exercem pressão transformadora.

Assim como o amor leva a criança a adquirir autoconfiança, a formação dos direitos básicos universais confere ao sujeito autorrespeito. No entanto, além da dedicação amorosa e do reconhecimento jurídico, tanto Hegel quanto Mead referiram-se a uma terceira forma de reconhecimento recíproco: a estima social. Enquanto o reconhecimento jurídico fundamentase nas propriedades universais dos seres humanos, a estima social fundamenta-se nas propriedades particulares, nas diferenças pessoais entre os seres humanos. Quanto mais essas propriedades singulares cooperam para os objetivos da sociedade, tanto mais a pessoa ou o grupo tem estima social:

A autocompreensão cultural de uma sociedade predetermina os critérios pelos quais se orienta a estima social das pessoas, já que suas capacidades e realizações são julgadas intersubjetivamente, conforme a medida em que cooperaram na implementação de valores culturalmente definidos (HONNETH, 2003, p. 200).

Nas sociedades estamentais, as pessoas gozavam de "honra" na medida em que conseguiam cumprir as expectativas coletivas de comportamento atreladas ao status de seu grupo. Com a transição para a modernidade, a "honra" é substituída pelo "prestígio" social, e o sujeito e sua biografia individual entram na disputa. A pessoa sabe-se valiosa na medida em que se sente reconhecida de forma particular, por realizações que ela não partilha com todos 
os demais seres humanos (por isso já é algo além da universalização da dignidade humana própria do reconhecimento jurídico).

Se, até então, as diferenças pessoas eram avaliadas de maneira coletivista (a honra do indivíduo era fixada a partir do estamento a que pertencia), com as revoluções burguesas e a superação gradativa da hierarquia tradicional de valores o conceito de "honra" passa a ser preenchido pelo conceito de "prestígio" (ou "reputação"). O grau de estima gozado socialmente pelo indivíduo passa a depender de suas realizações individuais, de como contribui para a implementação prática dos objetos culturais definidos pela sociedade. É exatamente por isso que "nas sociedades modernas, as relações de estima social estão sujeitas a uma luta permanente na qual os diversos grupos procuram elevar, com os meios da força simbólica e em referência às finalidades gerais, o valor das capacidades associadas à sua forma de vida" (HONNETH, 2003, p. 208-209, grifo ausente no original).

Portanto, a partir do momento em que o indivíduo pode atribuir a si próprio o mérito de realizações conforme os objetivos culturalmente definidos da sociedade, "vai de par com a experiência da estima social uma confiança emotiva na apresentação de realizações ou na posse de capacidades que são reconhecidas como 'valiosas' pelos demais membros da sociedade" (HONNETH, 2003, p. 210). Essa nova forma de autorrealização prática está fundada na estima e advém da comunidade de valores (solidariedade social), como a autoconfiança e o autorrespeito, que advêm, respectivamente, das relações amorosas e das relações jurídicas.

\section{Capítulo III: a judicialização da política como estratégia de reconhecimento na luta por estima social}

Tanto na filosofia política de Charles Taylor, quanto na de Axel Honneth, o reconhecimento é intersubjetivo, isto é, demanda uma relação entre dois ou mais sujeitos, na qual um busca ser reconhecido pelo outro, tendo o não reconhecimento consequências desfavoráveis para o self. Moreira, com base em Taylor, afirma que "a identidade e o reconhecimento não foram devidamente problematizados na Modernidade”, razão pela qual "com o fim das hierarquias sociais (pré-modernas), tornou-se de suma importância definir em que medida e de que modo o reconhecimento faz parte da construção de identidades individuais e coletivas" (2010, p. 18). Honneth trata a luta por reconhecimento como a "gramática moral dos conflitos sociais", afirmando como tese central que todo conflito social 
tem como motivo subjacente uma pretensão de reconhecimento. Em ambos (Taylor e Honneth), encontra-se a ideia, inspirada pelos escritos do jovem Hegel, de que uma pessoa somente se torna plenamente desenvolvida quando obtém reconhecimento de si por parte dos outros circundantes. A noção de reconhecimento é, nesse sentido, central para a vida humana, caracterizando um desenvolvimento espiral da personalidade em que a cada novo patamar o indivíduo obtém uma percepção mais ampla da sua própria identidade.

De acordo com Moreira (2010, p. 27), "o texto constitucional estabelece a linguagem comum para a construção do reconhecimento intersubjetivo", definindo os horizontes simbólicos do campo social. Honneth apresenta sua teoria das três dimensões do reconhecimento intersubjetivo - amor, direito e solidariedade -, sendo:

[...] a adjudicação de direitos (fase do direito) e a solidariedade (orientação comum por valores comunitários) como aquelas privilegiadas pela presente discussão: a relação entre o dirigismo-valorativo-constitucional e a construção da cidadania, ou seja, o constitucionalismo brasileiro e o desenvolvimento da identidade cidadã do indivíduo que compõe a comunidade estatal (MOREIRA, 2010, p. 29).

Nesse contexto, é possível a reflexão de que a judicialização da política, quando promovida por movimentos sociais e grupos minoritários, representa uma luta por reconhecimento em sua terceira dimensão, a busca por estima social, conforme a tipologia de Honneth. Moreira afirma que a tese de Charles Taylor acerca das consequências do não reconhecimento ou do reconhecimento errôneo (a autoprojeção de identidades falsas, distorcidas ou redutoras) "pode ser utilizada como uma lente privilegiada para a leitura e discussão sobre a exclusão de enorme parcela da sociedade que não se (vê) reconhece na Constituição” (MOREIRA, 2010, p. 29). Ao mesmo tempo, a tipologia de Axel Honneth também é relevante na articulação entre dirigismo constitucional, política de reconhecimento e sentimento constitucional, eis que a interpretação da Constituição passou a ser um elemento de disputa no Brasil contemporâneo, gerando conflitos sociais pautados na terceira dimensão do reconhecimento - a busca por estima social.

Nesse sentido, Moreira questiona: “qual o papel da Constituição, então, além daquele destacado pela tese da sua programaticidade dirigente exposta desde Canotilho e desenvolvida no Brasil, com ênfase na atuação da Jurisdição Constitucional, por autores como Streck?” (2010, p. 30). O próprio autor responde que o texto constitucional tem o condão de impulsionar a "construção de uma identidade simbólica, aberta e relacional" (2010, p. 30). Mas, ao mesmo tempo, na medida em que a própria interpretação constitucional está em permanente discussão, a Constituição passa a ser elemento de disputa entre os diversos grupos 
de interesse na sociedade, e a judicialização da política passa a compor uma estratégia relevante na luta dos grupos sociais pela proteção dos seus interesses. Muitos valores morais que, segundo Moreira, estruturam o texto constitucional são plurívocos - e o são justamente por serem morais, não jurídicos, chegando a se comportar como "envelopes vazios".

Assim, o próprio conteúdo positivado da Constituição está em permanente disputa, pois os grupos de interesse buscam preencher esses "envelopes vazios" de formas diferentes. Isso transforma a Constituição numa peça central da luta contemporânea por estima social no Brasil, utilizando-se aqui a ideia de estima a partir da tipologia do reconhecimento de Honneth.

De fato, ao adaptar as teorias de Honneth e Taylor à realidade brasileira, "a Constituição pode ser considerada o pano de fundo moral para o reconhecimento da cidadania”, conforme afirma Moreira (2010, p. 30). Ao mesmo tempo, a constante disputa em torno da interpretação da Constituição transforma-a numa peça central dos conflitos sociais no Brasil contemporâneo. Nesses termos, o pano de fundo desses conflitos sociais no Brasil passa a ser a busca por estima social, conforme a tipologia de Honneth, funcionando a Constituição e suas possibilidades de interpretação não apenas como pano de fundo (pois o elemento subjacente aos conflitos sociais é, na perspectiva tanto de Honneth quanto de Taylor, o reconhecimento), mas sim como peça central, uma "Rainha" no tabuleiro de xadrez (não o xadrez em si) que é o jogo político.

Portanto, neste trabalho concorda-se com Moreira no sentido de não apontar a Jurisdição Constitucional como o eixo central de uma Teoria da Constituição adequada a países periféricos de Modernidade tardia, sendo também necessário enfatizar o papel de uma cidadania ativista. "O dirigismo assumido pelo discurso transformador da realidade da Constituição de 1988, além da postura garantidora e efetivadora da Jurisdição Constitucional, depende fundamentalmente do estímulo de um sentimento constitucional dos cidadãos - e não de subcidadãos - brasileiros" (MOREIRA, 2010, p. 41). Ao mesmo tempo, ampliando-se a visão de Moreira sobre o papel da Constituição na ética do reconhecimento, percebe-se que a Constituição não é apenas o pano de fundo para o reconhecimento da cidadania plena para os grupos historicamente marginalizados, tendo em vista que a interpretação constitucional está em permanente disputa; o que constitui o pano de fundo para o reconhecimento da cidadania plena é a busca por estima social, conforme tipologia de Honneth, busca esta que atualmente encontra no texto constitucional um elemento estratégico de disputa - mas não o único, 
porque, ao mesmo tempo em que movimentos sociais e grupos minoritários judicializam a política disputando a interpretação da Constituição, também disputam representatividade na mídia, nos aparelhos sindicais e de classe, nas Universidades e na produção intelectual, entre outras instâncias.

Carvalho (2004), a partir do modelo de análise empírica desenvolvido por Neal Tate e T. Vallinder em The Global Expansion of Judicial Power, procurou investigar que condições políticas permitem o surgimento da judicialização. Aplicando os dados de Tate e Vallinder ao Brasil, Carvalho lista as seguintes condições:

1) Democracia - é impossível compatibilizar governos autoritários com a expansão do poder judicial; 2) Separação dos poderes - a existência de uma distinção de competências entre os três ramos do poder é um pressuposto para a judicialização; 3) Direitos políticos - a existência de direitos políticos reconhecidos pelo texto constitucional é recorrente nos países em que ocorre o fenômeno da judicialização; 4) O uso dos tribunais pelos grupos de interesse - os mais diversos grupos da sociedade passam a considerar o Judiciário e, sobretudo, a Jurisdição Constitucional como um caminho para a realização de seus objetivos; 5) O uso dos tribunais pela oposição - “os partidos de oposição, não podendo barrar as alterações realizadas pela maioria, utilizam-se dos tribunais para frear, obstaculizar e até mesmo inviabilizar as alterações em curso" (CARVALHO, 2004, p. 119); 6) Inefetividade das instituições majoritárias - quanto mais incapazes essas instituições forem em satisfazer as demandas sociais, tanto mais "alguns tribunais, diante da inércia dos políticos e da impossibilidade de negarem uma decisão, são obrigados a pôr um fim em conflitos que deveriam ser resolvidos no âmbito político" (CARVALHO, 2004, p. 120).

Deste modo, levando-se em consideração sobretudo a quarta condição (uso dos tribunais pelos grupos de interesse), "para que se verifique um ambiente propício à judicialização é provável que os grupos de interesses tenham uma boa parcela de participação nas ações judiciais" (CARVALHO, 2004, p. 118). Para testar a hipótese provável, o autor realiza uma análise empírica com 2.813 Ações Diretas de Inconstitucionalidade ajuizadas perante o Supremo Tribunal Federal, concluindo que "os números demonstram uma participação efetiva dos grupos de interesse na utilização das ADINs como instrumento de defesa de seus interesses" (CARVALHO, 2004, p. 119). 
Logo, percebe-se que a judicialização da política, enquanto mecanismo de disputa para proteção de interesses, tem sido uma estratégia central na luta por estima social no Brasil. Na nova conformação do Estado Democrático de Direito,

[...] o Judiciário é tão responsável quanto os demais Poderes estatais pela consecução dos objetivos fundamentais da República Federativa do Brasil. Sendo poder constituído, evidentemente subordinado à vontade constituinte, não tem o direito de sentir-se alheio ao projeto de edificar uma sociedade livre, justa e solidária (GERVASONI, LEAL, 2013, p. 65).

Um exemplo relevante é o julgamento do Supremo Tribunal Federal que criminalizou a homofobia, em ação ajuizada por uma Associação representativa de gays e lésbicas. A inércia da classe política em dar andamento ao debate na esfera legislativa levou um grupo de interesse (no caso, o movimento social de gays e lésbicas) a provocar o Judiciário com o objetivo de ver seus interesses protegidos. De acordo com Barreto (2016, p. 211-212), o recurso ao chamado Direito Penal dos Vulneráveis está associado à terceira esfera da luta por reconhecimento descrita por Honneth (solidariedade), em razão da função simbólica do Direito Penal. Isso porque a luta por reconhecimento jurídico teria se completado, do ponto de vista formal, com a constituição do Direito Penal de matriz liberal (BARRETO, 2016, p. 225).

Dessa forma, a mobilização de grupos minoritários em busca de estima social (dimensão da solidariedade) os tem levado a se apropriar da judicialização da política e da disputa pela interpretação constitucional como uma estratégia de reconhecimento e de elevação de sua estima social, o que contribui para o aperfeiçoamento do sentimento constitucional no Brasil, pois o constitucionalismo dirigente não está apenas nas mãos da Jurisdição Constitucional, mas também nas mãos do povo, em pleno exercício da cidadania ativista (MOREIRA, 2010).

Por fim, é importante discutir as diferenças entre judicialização da política e ativismo judicial. O Judiciário, na Modernidade, também tem um caráter político, decorrente da sua capacidade de fiscalizar a constitucionalidade dos atos normativos dos demais poderes. Segundo Gervasoni e Leal, "tal função coloca o Judiciário em pé de igualdade com os demais poderes em uma das dimensões mais importantes do sistema político: o processo decisório de estabelecimento de normas (leis e atos executivos) capaz de impor comportamentos" (2013, p. 80). Com a redemocratização do país e a promulgação da Constituição de 1988, estabeleceuse um novo cenário nacional, marcado pela ampliação dos direitos fundamentais, pelo aumento dos conflitos coletivos e pelo reconhecimento dos deveres estatais perante os 
cidadãos, o que passou a exigir "uma jurisdição atuante, capaz de assegurar a observância à Constituição, ainda que precise impor isso ao Estado" (GERVASONI, LEAL, 2013, p. 87$88)$.

A judicialização da política é uma consequência necessária desse cenário. Não é algo que o Judiciário poderia recusar. A amplitude dos direitos fundamentais, a inefetividade das instituições majoritárias e a inafastabilidade do acesso à tutela jurisdicional fizeram que o Judiciário e a Jurisdição Constitucional fossem "envolvidos em um contexto que é resultado da conjugação de uma série de fatores e opções em termos de ordenamento, cuja decisão jamais lhes coube, já que se dá por um processo de conformação histórica e determinada pelo constituinte" (GERVASONI, LEAL, 2013, p. 89).

Segundo as autoras, a judicialização da política (resultado necessário do atual arranjo constitucional, das determinações do constituinte) é indevidamente confundida com o ativismo judicial. $\mathrm{O}$ ativismo consiste numa postura da Corte Constitucional de ampliar o texto constitucional (como ocorreu no julgamento do Supremo Tribunal Federal que reconheceu as uniões homoafetivas), ao contrário da judicialização, em que o Tribunal Constitucional é simplesmente arrastado por uma série de fatores sobre os quais não tinha margem de escolha (GERVASONI, LEAL, 2013, p. 112). Ainda conforme as autoras,

\footnotetext{
[...] o termo ativismo é marcado de preconceitos, utilizado, não raro, como argumento retórico para criticar a atuação jurisdicional contrária a interesses particularizados e para disputar poder, não sendo, talvez nem de longe, o grande vilão das democracias contemporâneas (ao contrário da forma com que por vezes é tratado) (GERVASONI, LEAL, 2013, p. 125).
}

Nessa linha de raciocínio, as críticas superlativas ao ativismo judicial funcionam como cortina de fumaça para a principal disfunção da democracia brasileira: a crise de representatividade entre eleitores e eleitos, o que demanda uma reforma política, "a qual, definitivamente, não pode ser feita pelos juízes” (GERVASONI, LEAL, 2013, p. 125).

\section{Considerações finais}

Não existe apenas uma Teoria da Constituição, mas sim Teorias da Constituição, sendo necessário refletir sobre o arranjo teórico mais adequado para um contexto de Modernidade tardia, como o brasileiro, que não assistiu ao desenvolvimento pleno de um Estado Social, pois os direitos sociais não são garantidos para uma massa gigantesca da população, enquadrada que está numa condição histórica de marginalização e subcidadania. Nesse sentido, a tese de Moreira $(2008,2010)$ fornece uma Teoria da Constituição adequada 
ao Brasil - país periférico de Modernidade tardia - ao enfatizar a relevância não apenas da Jurisdição Constitucional (numa hermenêutica preocupada com a concretização dos valores morais da pessoa humana), mas também do povo e dos movimentos sociais (numa cidadania ativista apta a impulsionar o cumprimento das promessas constitucionais e, portanto, a promover o chamado sentimento constitucional).

Aplicando as teorias do reconhecimento de Taylor e Honneth à realidade brasileira, Moreira afirma que "a Constituição pode ser considerada o pano de fundo moral para o reconhecimento da cidadania" (2010, p. 30). Buscando-se ampliar essa visão, este trabalho trouxe a perspectiva de que a interpretação constitucional passou a ser no Brasil peça central de uma luta maior - a luta por estima social (conforme tipologia de Axel Honneth) promovida por movimentos sociais e grupos de interesse. A Constituição passa a ser elemento de disputa entre os diversos grupos de interesse na sociedade, e a judicialização da política, nesse cenário, passa a compor uma estratégia relevante na luta dos grupos sociais pela proteção dos seus interesses, como comprovado empiricamente pela pesquisa de Carvalho (2004) e simbolizado, inclusive, pelo recente julgamento do Supremo Tribunal Federal referente à criminalização da homofobia.

\section{Referências bibliográficas}

BARRETO, Daniela Lima. O direito penal dos vulneráveis: uma análise crítica da busca do reconhecimento por meio do direito penal. Rio de Janeiro: Lumen Juris, 2016.

BOBBIO, Norberto. A era dos direitos. Rio de Janeiro: Campus, 2004.

CANOTILHO, J. J. Gomes. Constituição dirigente e vinculação do legislador. Coimbra: Almedina, 2001.

CARVALHO, Ernani Rodrigues de. Em busca da judicialização da política no Brasil: apontamentos para uma nova abordagem. Revista de Sociologia e Política, Curitiba, n ${ }^{\mathrm{o}} 23$, p. 115-126, nov. 2004.

GERVASONI, Tássia Aparecida; LEAL, Mônia Clarissa Henrig. Judicialização da política e ativismo judicial na perspectiva do Supremo Tribunal Federal. Curitiba: Multideia, 2013.

HONNETH, Axel. Luta por reconhecimento: a gramática moral dos conflitos sociais. Trad. Luiz Repa. São Paulo: Ed. 34, 2003.

MATTOS, Patrícia. A sociologia política do reconhecimento: as contribuições de Charles Taylor, Axel Honneth e Nancy Fraser. São Paulo: Annablume, 2006. (Crítica contemporânea).

MOREIRA, Nelson Camatta. Constitucionalismo dirigente no Brasil: em busca das promessas descumpridas. Revista de Direitos e Garantias Fundamentais, Vitória, n. 3, p. 87-128, jul./dez. 2008. 
MOREIRA, Nelson Camatta. A filosofia política de Charles Taylor e a política constitucional de Pablo Lucas Verdú: pressupostos para a construção do sujeito constitucional. Revista de Direitos e Garantias Fundamentais, Vitória, no 8, p. 15-54, 2010.

SANTOS, Boaventura de Sousa. Prefácio do Volume 1. In: SANTOS, Boaventura de Sousa (Org.). Democratizar a democracia: os caminhos da democracia participativa. Rio de Janeiro: Civilização Brasileira, 2002. Coleção Reinventar a emancipação social: para novos manifestos, vol. 1.

SAYEG, Ricardo; BALERA, Wagner. O capitalismo humanista: filosofia humanista de direito econômico. Petrópolis: KBR, 2011.

TAYLOR, Charles. Argumentos filosóficos. São Paulo: Loyola, 2000.

VERDÚ, Pablo Lucas. Sentimento constitucional: aproximação ao estudo do sentir constitucional como modo de integração política. Trad. Agassiz A. F. Rio de Janeiro: Forense, 2004. 